\title{
Safety and Indicative Effectiveness of Porcine Corneal Lenticular Implants in Patients with Advanced Keratoconus and Post Lasik Ectasia: A Retrospective Clinical Study
}

\author{
Ahmed El-Massry (D) \\ Osama Ibrahim \\ Moones Abdalla \\ Ihab Osman \\ Shahira Mahmoud \\ Department of Ophthalmology, \\ Alexandria Faculty of Medicine, \\ Alexandria, Egypt
}

Correspondence: Ahmed El-Massry

Department of Ophthalmology, Alexandria Faculty of Medicine, Champollion Street, Al Attarin, Alexandria, Egypt

Tel +2 01222152435

Email ahmad.elmassry@gmail.com
Purpose: This study aimed to evaluate the safety and feasibility of implanting decellularized porcine corneal lenticules in a femtosecond laser-assisted pocket for patients with advanced keratoconus and post-Lasik ectasia.

Methods: This is a retrospective clinical study of implanting a porcine corneal lenticular implant in seven eyes: six with advanced keratoconus and clear cornea and one with advanced post-Lasik ectasia with a follow-up for 12 months. The lenticules are extracted from porcine tissue, subjected to a decellularization process, intensely cross-linked, sterilized and packed. They are $7 \mathrm{~mm}$ in diameter with at 100-120-micron thickness. The femtosecond laser was used to create an intra-stromal pocket, and then the lenticules were implanted inside the pocket followed by corneal cross-linking 3 months later for six out of seven eyes. Results: Five patients had keratoconus (6 eyes) and one patient (one eye) had post-Lasik ectasia. Visual acuity improved in all patients except for one case at 6 and 12 months and this was statistically significant $(\mathrm{P}=0.002$ and 0.007$)$. At one-year follow-up, the mean central corneal thickness increased from $389.43 \pm 45.41$ to $429.33 \pm 63.20 \mu \mathrm{m}$, the maximum keratometry decreased from $64.8 \pm 5.11$ to $62.82 \pm 6.16 \mathrm{D}$, the mean corneal resistance factor (CRT) increased from 5.67 to 8.42 , and the total higher-order aberrations decreased from 1.80 to 1.16 . Both changes in the CCT and CRF were statistically significant. One eye had wrinkles and opacified graft, and it was exchanged 3 months postoperatively.

Conclusion: Porcine corneal lenticules implantation is immunologically safe and well tolerated in patients with advanced keratoconus and post-Lasik ectasia and may be feasible as an alternative to keratoplasty.

Keywords: keratoconus, keratoplasty, femtosecond, ectasia

\section{Introduction}

Keratoconus is a bilateral, often asymmetric progressive disorder of the cornea that causes thinning and protrusion of the cornea. Vision is compromised because of high and irregular astigmatism. ${ }^{1,2}$ The early stages of the disease can be managed with glasses, rigid contact lenses, or intracorneal ring segments (ICRS) implantation, usually combined with corneal cross-linking. ${ }^{3}$ Corneal transplantation, either penetrating or lamellar keratoplasty, is reserved for eyes with severe disease or those who do not tolerate rigid contact lenses. ${ }^{4}$ The prognosis of keratoplasty in keratoconus is good in comparison to other diseases ${ }^{5,6}$ However, severe visual loss 
can occur due to either intra or postoperative complications, such as graft failure, rejection, infection, high astigmatism, suture-related complications and recurrence of keratoconus in the donor tissue. ${ }^{4,7,8}$

Transplantation of isolated Bowman layer (BLT) has been introduced recently as an alternative to keratoplasty in advanced keratoconus. ${ }^{9}$ This procedure aims to flatten the cornea, stop the progression of the disease, and increase the tolerance to contact lens. ${ }^{10,11}$

The Bowman layer graft is prepared from either whole globes or from poor quality corneal grafts. Manual preparation of the grafts is technically challenging with a $30 \%$ failure rate. ${ }^{12}$ The implantation of the isolated Bowman layer involves creating an intra-stromal pocket, which can be difficult in cases with advanced corneal thinning and can result in corneal perforation. A femtosecond laser has been recently used for creating the pocket to avoid this complication. $^{12}$

As the demand for donor corneas exceeds the supply, other strategies have been investigated. Swine have similar ocular anatomy and physiology, which is why they are used to model ocular diseases and develop novel therapies. ${ }^{13}$ Transplantation of swine corneal graft has shown to be a potential alternative to human corneal grafts. ${ }^{14}$ This study aimed to evaluate the safety, and indicative effectiveness of porcine corneal lenticules (Gebauer Medizintechnik $\mathrm{GmbH}$, Cleveland, $\mathrm{OH}$ ) (XENIA implants) in patients suffering from severe Keratoconus or post-LASIK ectasia with clear cornea in a femtosecond laser assisted pocket created in the corneal stroma.

\section{Subjects and Methods}

The study was conducted following the tenets of the Declaration of Helsinki and was approved by the institutional Ethics Committee of the Faculty of Medicine, Alexandria University, Egypt (Approval Number: 0304462). All patients signed a written informed consent before any intervention. Inclusions criteria included patients over 18 and less than 60 years old with keratoconus grade II, III or IV by Amsler Krumish classification or post-Lasik ectasia with clear cornea, diagnosed clinically and by corneal topography, intolerance to rigid contact lens, with no corneal opacities and patients preferring to avoid corneal transplantation. Exclusion criteria were abnormal corneal epithelium, previous keratoplasty, hydrops, cataract, active inflammation and/or infection of the eye or adnexa, glaucoma, autoimmune diseases, pregnancy and lactation.
The lenticules are manufactured from highly purified porcine corneas. The manufacturing process includes clearing all donors' cells and its elements followed by UVsterilization for cross-linking of the collagen fibrils. The lenticules are transparent disc-shaped with a 7-mm diameter and 100-120-micron thickness.

\section{The Procedure}

A 9-mm mid-stromal pocket was created using a femtosecond laser (VisuMax, Carl Zeiss Meditec AG). The dissection of the pocket was done using the spatula for SMILE procedure. The Gebauer ${ }^{\mathrm{TM}}$ Corneal Lenticule is inserted into the pocket using a McPherson forceps then centered with the spatula.

Postoperatively, the patients received Gatifloxacin $0.3 \%$, prednisolone acetate $1 \% ; 5$ times per day for five days to be tapered gradually on five-day schedule and lubricants for three months. Follow-up visits were scheduled at 1 day, 1 week, 1, 6, and 12 months postoperatively. All patients underwent Epi-off accelerated corneal crosslinking (CXL) 3 months after the Corneal Lenticular implantation except the case of post-Lasik ectasia because all cases except post-Lasik Ectasia showed progression of the $\mathrm{K}$ readings on Pentacam, despite the improvement in the thickness and the visual acuity. The CQL methods follow the standard protocol as shown in our previous work. $^{15}$

Before surgery and at follow-up visits, patients were examined for: Best spectacle-corrected visual acuity (BSCVA), slit-lamp examination, Scheimpflug-based corneal tomography (Pentacam HR; Oculus, Wetzlar, Germany), The iTrace wavefront aberrometry (Tracey Technologies, Inc.) to measure total higher order aberrations (Total HOA), spherical aberrations, and coma, Ocular Response Analyzer ${ }^{\circledR}$ (ORA; Reichert Ophthalmic Instruments, Buffalo, NY) to measure the corneal hysteresis $(\mathrm{CH})$ and the corneal resistance factor (CRF).

Statistical analyses were performed using Microsoft Excel, and a paired Student's $t$-test was used to test for statistical significance. A p-value less than 0.05 was considered statistically significant.

\section{Results}

Seven eyes of six patients ( 3 males and 3 females) were included in the study. All patients had keratoconus except for one patient (number 5 in tables) who had post-LASIK ectasia. The mean age of the patients was $27.67 \pm 9$ years. Preoperatively, the mean LogMAR visual acuity was $1.3 \pm$ 
Table I Preoperative and Postoperative LogMAR Visual Acuity and Central Corneal Thickness

\begin{tabular}{|c|c|c|c|c|c|c|c|c|c|}
\hline \multirow{2}{*}{$\begin{array}{l}\text { Patient No/Sex/Age/ } \\
\text { FU }\end{array}$} & \multirow[t]{2}{*}{ Eye } & \multicolumn{4}{|c|}{ LogMAR Visual Acuity } & \multicolumn{4}{|c|}{ CCT } \\
\hline & & Preop & Im & $6 m$ & Iy & Preop & Im & $6 m$ & ly \\
\hline I/M/24/6 & OS & 1 & 0.7 & 0.3 & & 367 & 417 & 383 & \\
\hline $2 / F / 40 / 12$ & OD & 1.5 & 1.4 & 1.4 & 1.3 & 389 & 475 & 462 & 488 \\
\hline 3/F/I9/9 & OD & 0.1 & 1 & 0.7 & 0.5 & 369 & 399 & 416 & 394 \\
\hline $4 / M / 2 I / 12$ & OS & 1.4 & 0.5 & 0.4 & 0.4 & 329 & 390 & 426 & 390 \\
\hline $5 / F / 38 / 12$ & OS & 1.3 & 1.3 & 0.5 & 0.2 & 320 & 326 & 341 & 320 \\
\hline $6 / M / 24 / 12$ & OD & 1.3 & 1.4 & 0.5 & 0.5 & 454 & 498 & 479 & 470 \\
\hline $6 / M / 24 / 12$ & OS & 1.3 & 0.8 & 0.5 & 0.5 & 439 & 491 & 473 & 470 \\
\hline Mean & & 1.3 & 1.01 & 0.61 & 0.57 & 389.43 & 431.43 & 415.57 & 429.33 \\
\hline SD & & 0.17 & 0.36 & 0.37 & 0.38 & 45.41 & 61.32 & 51.78 & 63.20 \\
\hline Range & & $1-1.5$ & $0.5-1.4$ & $0.3-1.4$ & $0.2-1.3$ & $320-454$ & $326-498$ & $34 \mid-493$ & $320-488$ \\
\hline P-value & & & 0.1 & $0.002 *$ & $0.007^{*}$ & & $0.004 *$ & $0.009 *$ & $0.05^{*}$ \\
\hline
\end{tabular}

Note: *Statistically significant.

Abbreviations: M, males; F, Females; CCT, central corneal thickness.

0.17 , and the mean central corneal thickness (CCT) was $389.43 \pm 45.41 \mu \mathrm{m}$ (Table 1). The mean flattest K (Kf), Steepest K (Ks), and maximum keratometry (Kmax) were $53.23 \pm 5.11,58.06 \pm 3.77,64.8 \pm 5.11 \mathrm{D}$, respectively (Table 2). The mean $\mathrm{CH}$ and $\mathrm{CRF}$ were $7.01 \pm 1.82$, and $5.67 \pm 2.60$, respectively (Table 3 ). The mean total $\mathrm{HO}$, coma and SA were $1.8 \pm 1.89,1.33 \pm 1.82$, and $0.50 \pm 0.62 \mu$, respectively (Table 4 ).

All patients completed one year of follow-up except patient number 1 who only completed 6 months of followup. All surgical procedures were uneventful.

The graft was visualized using Slit-lamp biomicroscopy and Anterior Segment Computed Tomography (ASOCT) (Heidelberg Germany) in all patients after one month, three months, six months and 12 months after surgery. Case number 2 in tables had graft opacification and wrinkles immediately postoperatively that persisted for 3 months (Figure 1). The patient had undergone another lenticule implantation that was uneventful.

Visual acuity improved in all patients at 1 and 6 and 12 months, which was statistically significant at 6 and 12 months $(\mathrm{P}=0.002$ and 0.007$)$ except patient number 2 even after the second transplantation who showed only improvement in the BSCVA from counting fingers at $50 \mathrm{~cm}$ to $3 \mathrm{~m}$ only. The mean CCT increased to $431.43,415.57$, and $429.33 \mu$ at 1 and 6 and 12 months, respectively, that was statistically significant $(\mathrm{P}=0.004$, 0.009 , and 0.05) (Table 1). The mean Kf decreased to 49.41, 50.70, and 49.25 D at 1, 6 and 12 months, which was statistically significant at one month $(p=0.04)$. The mean Ks decreased to 53.51 and 55.49 and $55.05 \mathrm{D}$ at 1 , 6 and 12 months, which was statistically significant at one month $(\mathrm{p}=0.01)$. The mean $\mathrm{Kmax}$ decreased to 61.06 and 62.67 and $62.82 \mathrm{D}$ at 1, 6 and 12 months, respectively, which was statistically significant at one month $(\mathrm{p}=0.01)$ (Table 2). Comparative Scheimpflugbased corneal tomography of patients before and after porcine corneal lenticule implantation showed statistically significant improvement in the corneal Kmin, and Kmax.

The mean $\mathrm{CH}$ increased to $8.93,10$, and 9.05 at 1 and 6 and 12 months, which was statistically significant at one and six months $(\mathrm{p}=0.01$ and 0.01$)$. The mean CRF increased to $8.46,9.13$ and 8.42 , respectively, that was statistically significant $(\mathrm{p}=0.01,0.005$, and 0.05$)$. (Table 3) The mean total HO decreased to 1.51, 1.18 and 1.16 at 1 and 6 and 12 months, respectively. The mean coma decreased to $0.61,0.68$ and 0.76 at 1 and 6 and 12 months, respectively. The mean SA decreased to 0.36 , 0.21 and 0.26 at 1 and 6 and 12 months, respectively. The change in the total HO, coma, and SA was not statistically significant (Table 4). 
Table 2 Preoperative and Postoperative Keratometry

\begin{tabular}{|c|c|c|c|c|c|c|c|c|c|c|c|c|}
\hline \multirow[t]{2}{*}{ Patient } & \multicolumn{4}{|c|}{ Kf } & \multicolumn{4}{|c|}{ Ks } & \multicolumn{4}{|c|}{ Kmax } \\
\hline & Preop & Im & $6 m$ & $\begin{array}{c}\text { Last } \\
\text { FU }\end{array}$ & Preop & Im & $6 m$ & Last Fu & Preop & Im & $6 m$ & $\begin{array}{c}\text { Last } \\
\text { FU }\end{array}$ \\
\hline 1 & 59 & 54.1 & 55.3 & & 60 & 58.4 & 57.3 & & 72.4 & 66.2 & 66.8 & \\
\hline 2 & 54.9 & 53.7 & 49.9 & 52.1 & 55.1 & 54.1 & 55.7 & 56.1 & 64.5 & 60.1 & 62.6 & 62.1 \\
\hline 3 & 56.1 & 51.8 & 51.3 & 51.7 & 62.5 & 56.7 & 55.9 & 56.8 & 65.6 & 62.2 & 59.9 & 60.4 \\
\hline 4 & 57.2 & 45.8 & 51.4 & 53 & 62.5 & 52.8 & 53.9 & 57.7 & 69.1 & 65.6 & 69 & 59.6 \\
\hline 5 & 52.5 & 49.4 & 53 & 50.9 & 54.5 & 50.7 & 60.5 & 59.3 & 58.5 & 62.3 & 60.5 & 59.3 \\
\hline $6 \mathrm{OD}$ & 45 & 46.4 & 46.2 & 45.8 & 53.5 & 52.8 & 54.8 & 54.3 & 58.5 & 56.2 & 59.5 & 59.2 \\
\hline 6 OS & 47.9 & 44.7 & 47.8 & 47.9 & 58.3 & 49.1 & 60.4 & 60.4 & 65.3 & 54.8 & 60.4 & 60.7 \\
\hline Mean & 53.23 & 49.41 & 50.7 & 49.25 & 58.06 & 53.51 & 55.49 & 55.05 & 64.84 & 61.06 & 62.67 & 62.82 \\
\hline SD & 5.11 & 3.88 & 3.07 & 2.65 & 3.77 & 3.23 & 1.73 & 2.28 & 5.11 & 4.35 & 3.76 & 6.16 \\
\hline Range & $45-59$ & $\begin{array}{c}44.7- \\
54.1\end{array}$ & $\begin{array}{c}46.2- \\
55.3\end{array}$ & $\begin{array}{c}45.8- \\
52.1\end{array}$ & $\begin{array}{c}53.5- \\
62.5\end{array}$ & $\begin{array}{c}49.1- \\
58.4\end{array}$ & $\begin{array}{l}53- \\
57.8\end{array}$ & $\begin{array}{c}51.3- \\
57.6\end{array}$ & $\begin{array}{c}58.5- \\
72.4\end{array}$ & $\begin{array}{r}54.8- \\
66.2\end{array}$ & $\begin{array}{c}59.5- \\
69.0\end{array}$ & $\begin{array}{r}59.2 \\
75.2\end{array}$ \\
\hline P-value & & $0.04^{*}$ & 0.06 & 0.1 & & $0.01 *$ & 0.11 & 0.14 & & $0.03 *$ & 0.06 & 0.33 \\
\hline
\end{tabular}

Note: *Statistically significant.

Table 3 Preoperative and Postoperative Corneal Hysteresis and Corneal Resistance Factor Measurements

\begin{tabular}{|c|c|c|c|c|c|c|c|c|}
\hline \multirow[t]{2}{*}{ Patient } & \multicolumn{4}{|c|}{$\mathbf{C H}$} & \multicolumn{4}{|c|}{ CRF } \\
\hline & Preop & Im & $6 m$ & Iy & Preop & Im & $6 m$ & Iy \\
\hline I & 5.4 & 9 & 6.9 & & 2.7 & 7.4 & 5.9 & \\
\hline 2 & 9.9 & 9.7 & 16.1 & 13.1 & 10.1 & 8.6 & 15.5 & 12.1 \\
\hline 3 & 7.3 & 7.8 & 8.5 & 5.3 & 6.2 & 8.1 & 7.7 & 5.9 \\
\hline 4 & 5.7 & 9.2 & 11.1 & 11.1 & 3.4 & 8.7 & 9.3 & 8.6 \\
\hline 5 & 4.3 & 5.6 & 6 & 7.2 & 2.9 & 6 & 5.7 & 6.4 \\
\hline $6 \mathrm{OD}$ & 8.4 & 10.4 & 8.9 & 7.8 & 7.9 & 10.1 & 8.2 & 7.9 \\
\hline 6 OS & 8.1 & 10.8 & 12.5 & 9.8 & 6.5 & 10.3 & 11.6 & 9.6 \\
\hline Mean & 7.01 & 8.93 & 10.00 & 9.05 & 5.67 & 8.46 & 9.13 & 8.42 \\
\hline SD & 1.82 & 1.63 & 3.25 & 2.59 & 2.60 & 1.39 & 3.46 & 2.07 \\
\hline Range & 4.3-9.9 & $5.6-10.8$ & $6-16.1$ & $5.3-13.1$ & $2.7-10.1$ & $6-10.3$ & $5.7-15.5$ & $5.9-12.1$ \\
\hline$P$-value & & $0.01 *$ & $0.01 *$ & 0.16 & & $0.01 *$ & $0.005^{*}$ & $0.05^{*}$ \\
\hline
\end{tabular}

Note: *Statistically significant.

Abbreviations: $\mathrm{CH}$, Corneal hysteresis; $\mathrm{CRF}$, corneal resistance factor.

\section{Discussion}

Keratoconus is a common disorder that affects both sexes and all races. The prevalence in the literature is ranging from
50 to 2300 per $100000 .{ }^{16}$ A standard recommended treatment for advanced keratoconus is corneal transplant (DALK or PKP). ${ }^{4}$ Bowman layer transplantation (BLT) is recently 
Table 4 Preoperative and Postoperative High Order Aberrations

\begin{tabular}{|c|c|c|c|c|c|c|c|c|c|c|c|c|}
\hline \multirow[t]{2}{*}{ Patient } & \multicolumn{4}{|c|}{ Total HO } & \multicolumn{4}{|l|}{ Coma } & \multicolumn{4}{|l|}{ SA } \\
\hline & Preop & Im & $6 m$ & Iy & Preop & Im & $6 m$ & Iy & Preop & Im & $6 m$ & Iy \\
\hline 1.00 & 6.32 & 0.77 & 0.72 & & 5.74 & 0.68 & 0.52 & & 1.98 & 0.03 & 0.05 & \\
\hline 2.00 & 1.43 & 2.50 & 1.91 & 1.16 & 0.84 & 0.39 & 0.41 & 0.85 & 0.42 & 0.47 & 0.65 & 0.28 \\
\hline 3.00 & 1.02 & 1.79 & 0.94 & 1.68 & 0.56 & 0.34 & 0.44 & 0.92 & 0.18 & 0.28 & 0.19 & 0.38 \\
\hline 4.00 & 0.52 & 2.34 & 0.48 & 1.70 & 0.32 & 1.10 & 0.38 & 1.19 & 0.05 & 0.76 & 0.10 & 0.57 \\
\hline 5.00 & 0.54 & 0.42 & 0.64 & 0.67 & 0.21 & 0.10 & 0.46 & 0.52 & 0.18 & 0.14 & 0.09 & 0.08 \\
\hline $6 \mathrm{OD}$ & 1.78 & 1.44 & 1.75 & 1.42 & 0.98 & 1.10 & 1.44 & 1.02 & 0.43 & 0.27 & 0.18 & 0.10 \\
\hline 6 OS & 1.02 & 1.31 & 1.82 & 0.31 & 0.68 & 0.56 & 1.10 & 0.08 & 0.24 & 0.60 & 0.18 & 0.13 \\
\hline Mean & 1.80 & 1.51 & 1.18 & 1.16 & 1.33 & 0.61 & 0.68 & 0.76 & 0.50 & 0.36 & 0.21 & 0.26 \\
\hline SD & 1.89 & 0.71 & 0.57 & 0.52 & 1.82 & 0.35 & 0.39 & 0.37 & 0.62 & 0.24 & 0.19 & 0.18 \\
\hline Range & $\begin{array}{l}0.52- \\
6.32\end{array}$ & $\begin{array}{l}0.42- \\
2.50\end{array}$ & $\begin{array}{l}0.48- \\
1.91\end{array}$ & $\begin{array}{l}0.31- \\
1.70\end{array}$ & $\begin{array}{l}0.21- \\
5.74\end{array}$ & $\begin{array}{l}0.10- \\
1.10\end{array}$ & $\begin{array}{l}038- \\
1.44\end{array}$ & $\begin{array}{l}0.08- \\
1.19\end{array}$ & $\begin{array}{l}0.05- \\
1.98\end{array}$ & $\begin{array}{l}0.03- \\
0.76\end{array}$ & $\begin{array}{l}0.05- \\
0.65\end{array}$ & $\begin{array}{l}0.08- \\
0.57\end{array}$ \\
\hline P-value & & 0.75 & 0.48 & 0.73 & & 0.36 & 0.42 & 0.44 & & 0.69 & 0.33 & 0.95 \\
\hline
\end{tabular}

Abbreviations: HO, Higher order; SA, spherical aberrations.

introduced as a minimally invasive surgical treatment for advanced keratoconus to flatten the cornea, to stop the progression of keratoconus, and to increase tolerance to contact lenses so corneal transplantation can be avoided or postponed. ${ }^{9}$ The grafts are prepared from either donor tissues with poor endothelium or the anterior corneal buttons after harvesting the grafts for endothelial keratoplasty. ${ }^{17}$ The estimated success rate of the Bowman layer transplantation is about $84 \%$. Postoperatively, significant anterior corneal

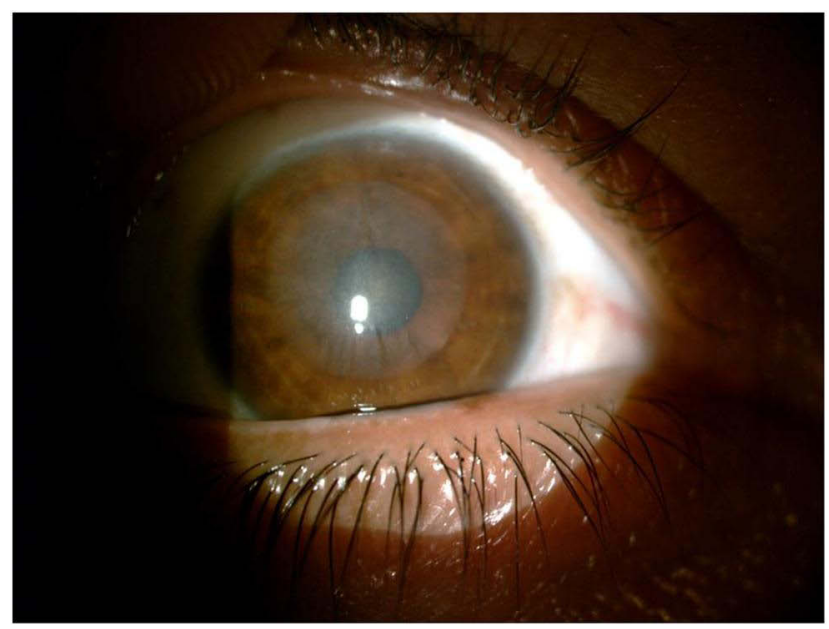

Figure I Three months after implantation shows wrinkles of the lenticule and hazy graft. flattening and visual acuity improvement stabilize for up to 7 years with few complications, mainly corneal hydrops. ${ }^{18}$ Although BLT is a good treatment option for keratoconus, it is not widely used for two reasons: harvesting the graft for BLT is technically challenging. Groeneveld-van Beek et al reported a $70 \%$ success rate. ${ }^{19}$ Secondly, corneal transplantation is not easily available in some areas of the world. A global survey on the accessibility of corneal transplantation found that about $53 \%$ of the world's population had no access to corneal transplantation. ${ }^{20}$

In the current study, we present the results of the transplantation of Porcine Lenticules, made of highly purified collagen fibers of porcine origin that were intensely crosslinked, in patients with keratoconus and post-LASIK ectasia.

Manual lamellar dissection is technically difficult in keratoconus due to corneal thinning and can be complicated by corneal perforation. Perforations occurred in $10 \%$ of cases during BLT using manual dissection techniques. ${ }^{10}$ The femtosecond laser has shown great success in channel creation for ICRS implantation. Ibrahim et al successfully implanted ICRS using femtosecond laser in 160 eyes with moderate keratoconus with no intra-operative complications. ${ }^{21}$ In the present study, we used a femtosecond laser to create a midstromal pocket at a depth of $100 \mu \mathrm{m}$ and no intra-operative complications using the femtosecond laser pocket creation were reported. 
Postoperatively, vision improved in all patients with no loss of BSCVA except for the second patient who had persistently poor vision even after the replacement of the opacified wrinkled flap. There was no statistically significant difference between the preoperative and postoperative keratometry at 6 and 12 months and higher-order aberrations. Because the number of eyes included in the study is small, the statistical significance may not be accurate and more studies with larger numbers are needed to confirm the present data.

The increased CCT in all eyes postoperatively allowed safe corneal cross-linking three months after the lenticule transplantation. Porcine corneal lenticular implants do not integrate with the corneal tissue, and progression of the ectasia can occur underneath the implants. In a case series of 20 eyes with successful BLT, three eyes of two patients developed corneal hydrops at $4.5,6$, and 6.5 years $^{11,22}$ postoperatively, so, corneal cross-linking might be necessary to stabilize the cornea and stop the progression of the keratoconus underneath the implants.

Although the graft was visualized by slit-lamp examination and ASOCT shows a hyper-reflective layer, this was not visually significant and did not result in visual complaints post-operatively or increase in corneal higher order aberrations.

Initially, the study aimed to assess the safety and efficacy of porcine corneal lenticules in advanced keratoconus with Amsler-Krumeich classification stages III and IV; ${ }^{23}$ however, patient number 6 had stage II in his right eye.

As porcine corneal lenticules are made from animal tissue, there is a potential risk for developing tissue rejection and immunological reaction. Patients need to be closely monitored after the withdrawal of topical steroids. None of the patients developed any immunological reaction or tissue rejection throughout the study period (twelve months). We did not use the lenticule of SMILE patients for three reasons; these lenticules are not cross-linked so their efficacy for strengthening the cornea is not guaranteed, and the thickness of the SMILE lenticules is variable depending on the patient's refraction, which will not give fixed results and as these lenticules are neither decellularized nor cross-linked, the reaction of the SMILE lenticules is not predictable in human eyes.

To the best of our knowledge, this is the first study on the transplantation of porcine collagen corneal lenticules as an alternative to BLT or DALK. The advantages of these implants (named Xenogenic Implants) are: surgery is done under topical anesthesia, short learning curve, easy implantation, short rehabilitation time, reversibility and in case of failure, still lamellar keratoplasty could be done. The limitations of the current study are the small sample size, absence of control group and the relatively short follow up. For the assessment of optical property and amount of scattering of this lenticule, visometry may be used. In addition, to evaluate the histologic changes and host immune reactions, confocal microscopy could be used. We recommend future studies to avoid these limitations.

Porcine corneal lenticules implantation is safe and well tolerated in patients with advanced keratoconus and postLasik ectasia. Further studies with a larger number of patients and longer follow-up are needed.

\section{Abbreviations}

ICRS, Intracorneal ring segments; BLT, Isolated Bowman layer; BSCVA, Best spectacle-corrected visual acuity; $\mathrm{CH}$, Corneal hysteresis; CRF, Corneal resistance factor; CCT, Central corneal thickness.

\section{Data Sharing Statement}

The datasets generated during and analysed during the current study are not available due to privacy/ethical restrictions but are available from the corresponding author on reasonable request.

\section{Ethics Approval and Consent to Participate}

All procedures performed in studies involving human participants were in accordance with the ethical standards of Alexandria Faculty of Medicine ethics committee and with the 1964 Helsinki declaration and its later amendments. The ethical approval was obtained from the ethics committee of Alexandria Faculty of Medicine, Alexandria, Egypt. A written informed consent was obtained from all individual participants included in the study.

\section{Disclosure}

Prof. Dr. Osama Ibrahim reports being a consultant for Zeiss, outside the submitted work. The authors declare no other conflicts of interest in this work.

\section{References}

1. Rabinowitz YS. Keratoconus. Surv Ophthalmol. 1998;42(4):297-319. doi:10.1016/S0039-6257(97)00119-7

2. Mas Tur V, MacGregor C, Jayaswal R, O’Brart D, Maycock N. A review of keratoconus: diagnosis, pathophysiology, and genetics. Surv Ophthalmol. 2017;62(6):770-783. doi:10.1016/j.survopht hal.2017.06.009 
3. Mohammadpour M, Heidari Z, Hashemi H. Updates on managements for keratoconus. $J$ Curr Ophthalmol. 2018;30(2):110-124. doi:10.1016/j.joco.2017.11.002

4. Parker JS, van Dijk K, Melles GR. Treatment options for advanced keratoconus: a review. Surv Ophthalmol. 2015;60(5):459-480.

5. Muraine M, Sanchez C, Watt L, Retout A, Brasseur G. Long-term results of penetrating keratoplasty. A 10-year-plus retrospective study. Graefes Arch Clin Exp Ophthalmol. 2003;241(7):571-576. doi:10.1007/s00417-003-0691-z

6. Claesson M, Armitage WJ. Ten-year follow-up of graft survival and visual outcome after penetrating keratoplasty in Sweden. Cornea. 2009;28(10):1124-1129. doi:10.1097/ICO.0b013e3181a2a7a6

7. Olson RJ, Pingree M, Ridges R, Lundergan ML, Alldredge C, Clinch TE. Penetrating keratoplasty for keratoconus: a long-term review of results and complications. $J$ Cataract Refract Surg. 2000;26(7):987-991. doi:10.1016/S0886-3350(00)00430-2

8. de Toledo JA, de la Paz MF, Barraquer RI, Barraquer J. Long-term progression of astigmatism after penetrating keratoplasty for keratoconus: evidence of late recurrence. Cornea. 2003;22(4):317-323. doi:10.1097/00003226-200305000-00008

9. van Dijk K, Parker J, Tong CM, et al. Midstromal isolated Bowman layer graft for reduction of advanced keratoconus: a technique to postpone penetrating or deep anterior lamellar keratoplasty. JAMA Ophthalmol. 2014;132(4):495-501. doi:10.1001/jamaophthalmol.2013.5841

10. van Dijk K, Liarakos VS, Parker J, et al. Bowman layer transplantation to reduce and stabilize progressive, advanced keratoconus. Ophthalmology. 2015;122(5):909-917. doi:10.1016/j.ophtha.2014.12.005

11. van Dijk K, Parker JS, Baydoun L, et al. Bowman layer transplantation: 5-year results. Graefes Arch Clin Exp Ophthalmol. 2018;256 (6):1151-1158. doi:10.1007/s00417-018-3927-7

12. García de Oteyza G, González Dibildox LA, Vázquez-Romo KA, et al. Bowman layer transplantation using a femtosecond laser. J Cataract Refract Surg. 2019;45(3):261-266. doi:10.1016/j.jcrs.2018.10.034

13. Stricker-Krongrad A, Shoemake CR, Bouchard GF. The miniature swine as a model in experimental and translational medicine. Toxicol Pathol. 2016;44(4):612-623. doi:10.1177/0192623316641784
14. Zhiqiang P, Cun S, Ying J, Ningli W, Li W. WZS-pig is a potential donor alternative in corneal xenotransplantation. Xenotransplantation. 2007;14 (6):603-611. doi:10.1111/j.1399-3089.2007.00432.x

15. Lee R, El-Massry A, El-Massry Y, Randleman JB. Bilateral, asymmetric keratoconus induced by thyrotoxicosis with long-term stability after corneal cross-linking. J Refractive Surg. 2018;34(5):354-356. doi:10.3928/1081597X-20180301-02

16. Krachmer JH, Feder RS, Belin MW. Keratoconus and related noninflammatory corneal thinning disorders. Surv Ophthalmol. 1984;28 (4):293-322. doi:10.1016/0039-6257(84)90094-8

17. Groeneveld-van Beek EA, Lie JT, van der Wees J, Bruinsma M, Melles GR. Standardized 'no-touch' donor tissue preparation for DALK and DMEK: harvesting undamaged anterior and posterior transplants from the same donor cornea. Acta Ophthalmol. 2013;91 (2):145-150. doi:10.1111/j.1755-3768.2012.02462.x

18. Tong CM, van Dijk K, Melles GRJ. Update on Bowman layer transplantation. Curr Opin Ophthalmol. 2019;30(4):249-255. doi:10.1097/ICU.0000000000000570

19. Groeneveld-van Beek EA, Parker J, Lie JT, et al. Donor Tissue preparation for bowman layer transplantation. Cornea. 2016;35 (12):1499-1502. doi:10.1097/ICO.0000000000000905

20. Gain P, Jullienne R, He Z, et al. Global Survey of Corneal Transplantation and Eye Banking. JAMA Ophthalmol. 2016;134 (2):167-173. doi:10.1001/jamaophthalmol.2015.4776

21. Ibrahim O, Elmassry A, Said A, Abdalla M, El Hennawi H, Osman I. Combined femtosecond laser-assisted intracorneal ring segment implantation and corneal collagen cross-linking for correction of keratoconus. Clin Ophthalmol. 2016;10:521-526.

22. Zygoura V, Birbal RS, van Dijk K, et al. Validity of Bowman layer transplantation for keratoconus: visual performance at 5-7 years. Acta Ophthalmol. 2018;96(7):e901-e902. doi:10.1111/aos.13745

23. Naderan M, Jahanrad A, Balali S. Histopathologic findings of keratoconus corneas underwent penetrating keratoplasty according to topographic measurements and keratoconus severity. Int J Ophthalmol. 2017;10(11):1640-1646.
Clinical Ophthalmology

\section{Publish your work in this journal}

Clinical Ophthalmology is an international, peer-reviewed journal covering all subspecialties within ophthalmology. Key topics include: Optometry; Visual science; Pharmacology and drug therapy in eye diseases; Basic Sciences; Primary and Secondary eye care; Patient Safety and Quality of Care Improvements. This journal is indexed on PubMed
Central and CAS, and is the official journal of The Society of Clinical Ophthalmology (SCO). The manuscript management system is completely online and includes a very quick and fair peer-review system, which is all easy to use. Visit http://www.dovepress.com/ testimonials.php to read real quotes from published authors. 